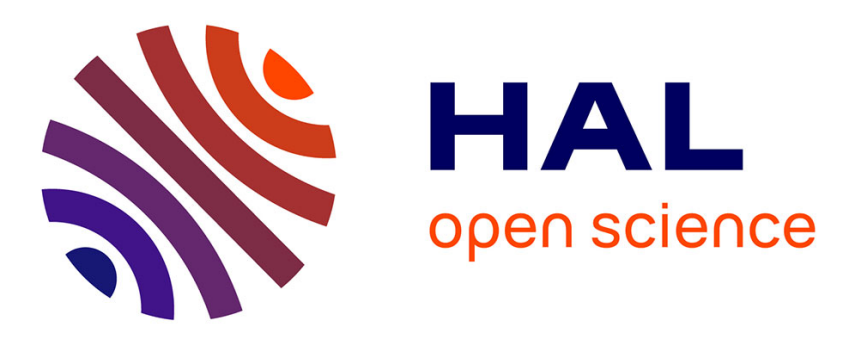

\title{
Synthesis of Cyclopentenones with C4-Quaternary Stereocenters via Stereospecific [3,3]-Sigmatropic Rearrangement and Applications in Total Synthesis of Sesquiterpenoids
}

\author{
Weiping Zhou, Arnaud Voituriez
}

\section{To cite this version:}

Weiping Zhou, Arnaud Voituriez. Synthesis of Cyclopentenones with C4-Quaternary Stereocenters via Stereospecific [3,3]-Sigmatropic Rearrangement and Applications in Total Synthesis of Sesquiterpenoids. Journal of the American Chemical Society, 2021, 10.1021/jacs.1c07966 . hal-03402779

\author{
HAL Id: hal-03402779 \\ https://hal.science/hal-03402779
}

Submitted on 25 Oct 2021

HAL is a multi-disciplinary open access archive for the deposit and dissemination of scientific research documents, whether they are published or not. The documents may come from teaching and research institutions in France or abroad, or from public or private research centers.
L'archive ouverte pluridisciplinaire HAL, est destinée au dépôt et à la diffusion de documents scientifiques de niveau recherche, publiés ou non, émanant des établissements d'enseignement et de recherche français ou étrangers, des laboratoires publics ou privés. 


\title{
Synthesis of Cyclopentenones with C4-Quaternary Stereocen- ters via Stereospecific [3,3]-Sigmatropic Rearrangement and Applications in Total Synthesis of Sesquiterpenoids
}

\author{
Weiping Zhou and Arnaud Voituriez* \\ Université Paris-Saclay, CNRS, Institut de Chimie des Substances Naturelles, UPR 2301, 91198 Gif-sur-Yvette, France.
}

\begin{abstract}
A cationic gold(I)-catalyzed asymmetric [3,3]-sigmatropic rearrangement of sulfonium leads after cyclization to cyclopentenones with a C4-quaternary stereocenter. Starting with simple vinyl sulfoxides and propargyl silane, numerous compounds were isolated with moderate to good yields and excellent enantiomeric excesses (26 examples). The application of this simple methodology allowed the efficient total synthesis of five natural sesquiterpenoids, including enokipodin A and B, hitoyopodin A, lagopodin A and the isocuparene-3,4-diol.
\end{abstract}

Stereoselective formation of quaternary carbon centers remains one of the biggest challenges in organic chemistry. The presence of four different carbon substituents on the same atom implies an important steric hindrance around the stereocenter and this may partially explain the limited number of methodologies developed. ${ }^{1}$ On the other hand, more and more natural products and APIs with at least one quaternary center are isolated and possess intrinsic biological properties of interest. ${ }^{2}$ Among them, C4-chiral cyclopentenone scaffolds deserve to be emphasized. Indeed, this motif is present in numerous natural products, and can be seen as a platform for more complex molecules (Scheme 1a). ${ }^{3}$ In addition to the inherent reactivity of the $\alpha, \beta$-unsaturated ketone for 1,2-and 1,4-additions, the acidic $\alpha$-position to carbonyl group allows easy selective functionalizations. However, the state-of-the-art methods for the synthesis of chiral C4-quaternary cyclopentenones are quite limited (Scheme 1b). For instance, cyclopentanones were formed through asymmetric metal-catalyzed conjugate additions ${ }^{1,4}$ to $\beta$-substituted cyclopentenones followed by an oxidative dehydrogenation step to recover the enone function. ${ }^{5}$ On the other hand, Nazarov cyclization/Wagner-Meerwein rearrangement of acyclic dienones furnish cyclopentenones with C4 and C5 stereogenic centers ${ }^{6 a, b}$ and Pauson-Khand reaction could deliver the same functionalized chiral products in efficient way but with a narrow substrate scope. ${ }^{6 c, d}$ We propose here to use a gold-catalyzed asymmetric [3,3]sigmatropic rearrangement starting from enantioenriched vinyl sulfoxide 1 and propargyl silane, to yield chiral 4-oxopentanal derivatives $\mathbf{2}$ with transfer of the chirality from the sulfur atom to the quaternary carbon center (Scheme 1c). In the last decade, numerous studies have demonstrated the synthetic interest of [3,3]-sigmatropic rearrangement for the synthesis of quaternary stereocenters, ${ }^{7}$ and specifically with sulfur-containing substrates. ${ }^{8}$ Indeed, after the development of gold-catalyzed processes, ${ }^{\text {aa-d }}$ charge-accelerated $[3,3]$-rearrangements were developed via interrupted Pummerer reaction/sigmatropic rearrangements. ${ }^{9 f-p}$
Scheme 1. Strategies Towards the Synthesis of Cyclopentenones with C4-Quaternary Stereocenters

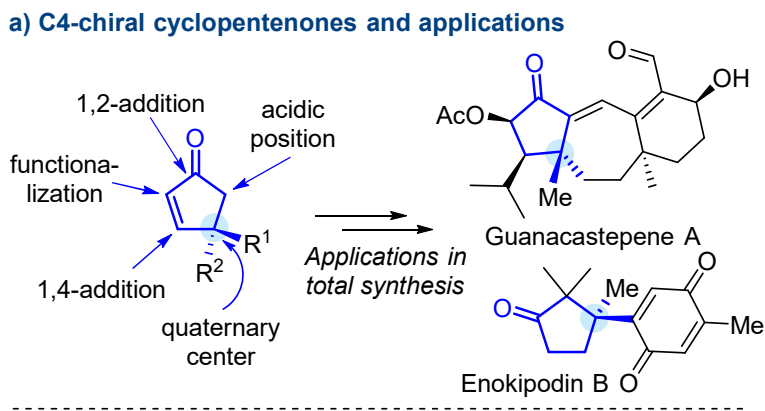

b) Available methodologies to access chiral cyclopentenones

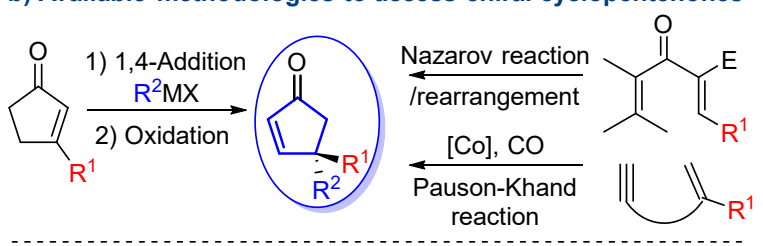

c) This work: asymmetric [3,3]-sigmatropic rearrangement

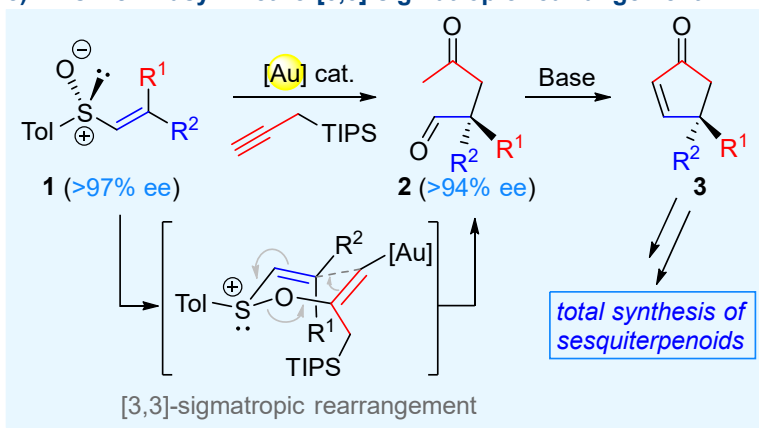

Our participation in this field was to use electron-rich arylalkynes and vinyl sulfoxides as partners, for the synthesis of 1,4-dicarbonyl derivatives. ${ }^{9 e}$ In the present study, we demonstrated that after the sigmatropic rearrangement, ke- 
toaldehydes 2 could be easily converted to C4-chiral cyclopentenones $\mathbf{3}$ and applied this methodology to the fast and efficient total syntheses of five sesquiterpenoids.

For the optimization of this reaction, we first screened different gold(I)-catalysts to produce $\mathbf{2 a}$, starting from vinyl sulfoxide ${ }^{10}(R)$-1a and triisopropyl(prop-2-yn-1-yl)silane in a $1 / 2$ ratio (Table 1 , entries $1-3$ ). Commercially available cationic JohnPhosAu(MeCN)SbF 6 catalyst $\left(\mathrm{L}_{1} \mathrm{AuSbF}_{6}\right)$ proved to be the most efficient catalyst (entry 3). Decreasing the relative stoichiometry to a $1 / 1.5$ ratio, $16 \mathrm{~h}$ at $30^{\circ} \mathrm{C}$, allowed to isolate product 2a in $63 \%$ yield (entries $3-5$ ). The use of $5 \mathrm{~mol} \%$ gold catalyst or triflimide decreased the conversion (entries 6-7, see SI for the full optimization Table). It is important to note the perfect chirality transfer from sulfur to carbon atom in all cases. The same reaction was then performed using optimized conditions (entry 4, Table 1), and the solvent was removed after completion (Scheme 2). Potassium carbonate and tert-butanol were added to the crude mixture to perform the intramolecular aldol condensation/elimination reaction, to afford 3a in 94\% yield. Overall, compound $(S)$-3a was isolated in a one pot transformation, in $59 \%$ yield and $97 \%$ ee. That confirms that this $\mathrm{Au}(\mathrm{I})$-catalyzed rearrangement, combined with an aldolization reaction is a very efficient process to yield highly enantioenriched cyclopentenones.
Table 1. Optimization of the Reaction Conditions

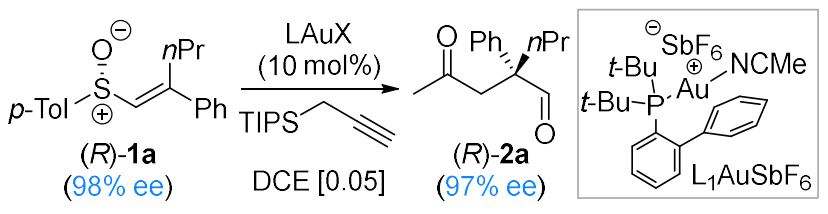

\begin{tabular}{llllll}
$\begin{array}{l}\text { en- } \\
\text { try }\end{array}$ & LAuX & $\begin{array}{l}\text { Subs- } \\
\text { trate } \\
\text { ratio }\end{array}$ & $\begin{array}{l}\mathrm{T} \\
\left({ }^{\circ} \mathrm{C}\right)\end{array}$ & $\begin{array}{l}\mathrm{t}(\mathrm{h}) \\
\text { Yield 2a } \\
(\%)^{\mathrm{a}}\end{array}$ \\
\hline 1 & $\mathrm{PPh}_{3} \mathrm{AuNTf}_{2}$ & $1 / 2$ & 20 & 60 & 59 \\
2 & $\mathrm{PPh}_{3} \mathrm{AuCl}_{\mathrm{AgSSF}}$ & $1 / 2$ & 20 & 60 & 62 \\
3 & $\mathrm{~L}_{1} \mathrm{AuSbF}_{6}$ & $1 / 2$ & 20 & 60 & 70 \\
4 & $\mathrm{~L}_{1} \mathrm{AuSbF}_{6}$ & $1 / 1.5$ & 30 & 16 & $68(63)^{\mathrm{b}}$ \\
5 & $\mathrm{~L}_{1} \mathrm{AuSbF}_{6}$ & $1 / 1$ & 30 & 16 & 36 \\
$6 \mathrm{c}$ & $\mathrm{L}_{1} \mathrm{AuSbF}_{6}$ & $1 / 1.5$ & 30 & 60 & $60(56)^{\mathrm{b}}$ \\
7 & $\mathrm{HNTf}_{2}$ & $1 / 1.5$ & 30 & 16 & 40
\end{tabular}

${ }^{a}$ NMR yield, with the use of dibromomethane as internal standard. ${ }^{b}$ Isolated yield. ${ }^{\mathrm{c}} 5 \mathrm{~mol} \%$ catalyst at $1 \mathrm{mmol}$ scale.

Scheme 2. Cyclization Step for the Formation of 3

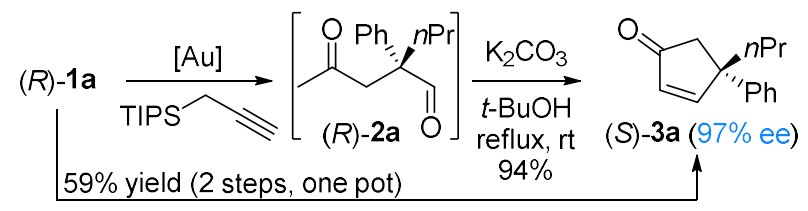

Scheme 3. Reaction Scope of the Catalytic Transformation for the Formation of C4-Chiral Cyclopentenones

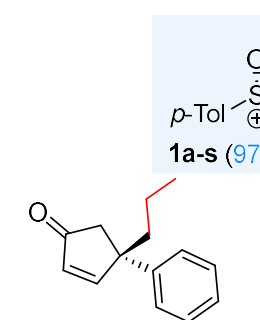

$(S)-3 a$

$59 \%, 97 \%$ ee

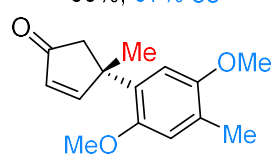

(S)-3e

$53 \%, 97 \%$ ee

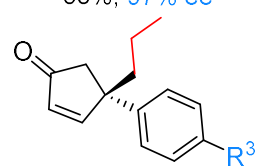

(S)-3h, $\mathrm{R}^{3}=\mathrm{Br}(\mathrm{S})-\mathbf{3 i}, \mathrm{R}^{3}=\mathrm{CO}_{2} \mathrm{Me}$

$63 \%, 98 \%$ ee $\quad 51 \%, 96 \%$ ee

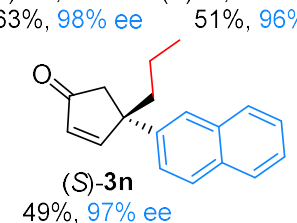

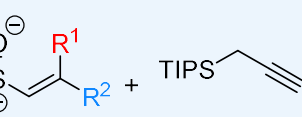

$99 \%$ ee)<smiles>Cc1ccc([C@]2([14CH3])C=CC(=O)C2)cc1</smiles>

(S)-3b

$51 \%, 97 \%$ ee<smiles>COc1ccc(C2(c3cc(OC)c(OC)cc3OC)C=CC(=O)C2)c(OC)c1</smiles>

$(R)-3 e$

$70 \%, 99 \% e e^{a}$

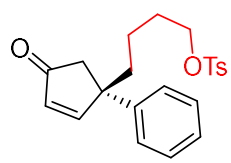

(S)-3j

$40 \%$, $98 \%$ ee

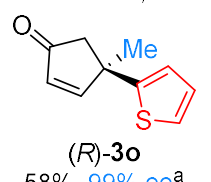

$58 \%, 99 \% e e^{a}$

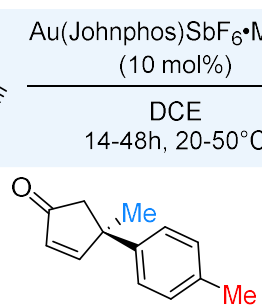

(R)-3b

$63 \%, 98 \% e e^{a}$<smiles>[Y14]C1(c2cc(OC)c(OC)c(OC)c2)C=CC(=O)C1</smiles>

(S)-3f $\mathrm{Me}$ $\quad \mathrm{CO}_{2} \mathrm{M}$

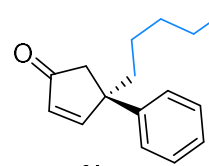

$(R)-3 \mathbf{k}$

$62 \%, 98 \% \mathrm{ee}^{\mathrm{a}}$

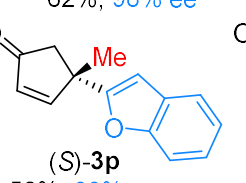

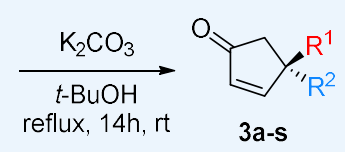
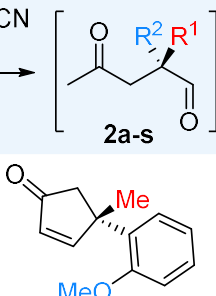

(S)-3c

$65 \%, 97 \%$ ee
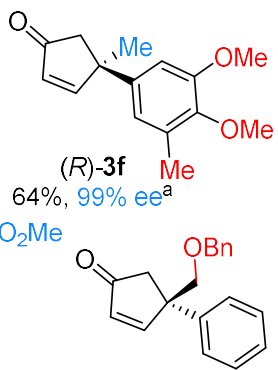

(R)-3। $57 \%, 98 \%$ ee

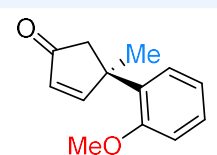

$(R)-3 \mathrm{c}$

$54 \%, 97 \% e e^{a}$

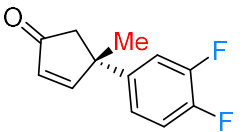

(S)-3g

$65 \%, 98 \%$ ee

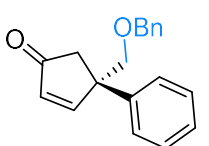

(S)-31

$58 \%, 98 \%$ ee

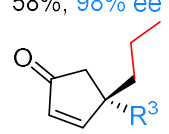

(R)-3p $50 \% .98 \% e e^{a}$

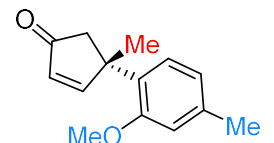

(S)-3d $50 \%, 96 \%$ ee

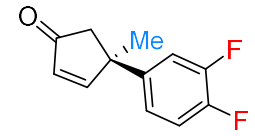

(R)-3g $62 \%, 98 \% e e^{a}$

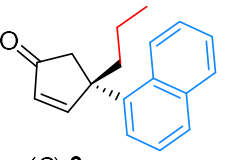

(S)-3m

$47 \%, 95 \%$ ee

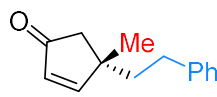

(R)-3q, $\mathbf{R}^{3}=\mathrm{Cy}(\mathrm{S})-\mathbf{3} \mathbf{r}, \mathrm{R}^{3}=n-\mathrm{C}_{7} \mathrm{H}_{15} \quad$ (S)-3s $63 \% .94 \%$ ee $\quad 65 \%$. $95 \%$ ee $\quad 64 \%, 97 \%$ ee 
With these optimized reaction conditions, we studied the scope of the reaction. Importantly, starting from the $E$-vinyl sulfoxides, compounds $(S)-3$ were isolated, while $Z$-isomers of 1 produce $(R)-3$ products, with the same excellent conservation of the enantiomeric excesses. Due to its occurrence in natural products, we first applied this method to the synthesis of 4-aryl-4-methylcyclopentenone products 3b-3g (Scheme 3). Starting with diversely substituted aromatic groups, the chirality transfer was always excellent, furnishing compounds $\mathbf{3 b}$-g in up to $70 \%$ yield and $96-99 \%$ ee. Functionalized substrates such as $p$-bromo-aryl or $p$-ester-aryl derivatives smoothly gave the rearrangement products $(S)-\mathbf{3 h}$,i (up to $98 \%$ ee). Tolylsulfonate, alkylester and benzyl ether-functionalized substrates were also well tolerated in this transformation (compounds $\mathbf{3 j - 1}$ ). The later examples highlight the wide tolerance of diversely functionalized substrates in our mild reaction conditions. More sterically hindered naphthyls and heteroaryls, such as thiophene and benzofuran groups, delivered the corresponding chiral cyclopentenones 3m-p in up to 58\% yield and 95-99\% ee. Finally, this methodology was efficiently extended to the use of $\beta, \beta$-dialkyl-vinyl sulfoxide 1q-s, for the formation of 3q-s, in 63-65\% yield (94-97\% ee).

Concerning the mechanism of this transformation, reaction started with the gold-activation of propargyl silane (Scheme 4a). The presence of silicon is very important for the success of this transformation, due to the well known properties of silicon to stabilize $\beta$-positive charge (intermediate $\mathbf{I}^{\prime}$ ). ${ }^{11 \mathrm{a}-\mathrm{c}}$ This substrate has already been used sucessfully in organic synthesis and in [3,3]-sigmatropic rearrangements. ${ }^{11 \mathrm{~d}-g}$ Subsequent addition of vinyl sulfoxide $\mathbf{1}$ to $\mathrm{Au}(\mathrm{I})$-activated alkyne (I) furnished sulfonium intermediate (II). After [3,3]-sigmatropic rearrangement through a chair-like transition state, thionium ion (III) could be formed. Hydrolysis and protodemetallation steps gave chiral 1,4-dicarbonyls 2. Moreover, this transformation with the traceless chiral sulfoxide auxiliary allowed a stereospecific reaction: the double bond geometry of vinyl sulfoxide determines the absolute configuration of the carbon stereogenic center (Scheme $4 \mathrm{~b}$ and SI for details on substrate syntheses ${ }^{10}$ ).

Starting from suitably decorated substrates, this methodology could easily be applied in the total synthesis of numbers of naturally occurring secondary metabolites sesquiterpenes such as cuparenes, herbertenes and others. ${ }^{12} \mathrm{We}$ decided to focus our attention on the synthesis of natural products whose total syntheses are rarely reported and/or laborious, using the established methodologies (Scheme 5). We first applied the newly developed methodology to the total synthesis of Lagopodin A and Hitoyopodin A, isolated from the mushroom Coprinopsis cinerea (Scheme 5a, left). ${ }^{13 a, b}$ Starting with $(S)$-3e, easily obtained from the corresponding vinyl sulfoxide $(E)-\mathbf{1 e}$, compound $\mathbf{4}$ was isolated in a three steps sequence including a copper 1,4-addition of a methyl group, a Pd-mediated oxidation ${ }^{5}$ and a nickel-catalyzed addition of trimethylaluminum. Final CAN (ceric ammonium nitrate)-oxidation furnished Lagopodin A $(18 \%$ overall yield, 7 steps). From the same intermediate 4, a sequence combining the demethylation of aryl methoxy groups and the cyclization promoted by $\mathrm{BBr}_{3}$ delivered Hitoyopodin A in $15 \%$ overall yield, in 7 steps.

\section{Scheme 4. Mechanism and Proposed Transition State}

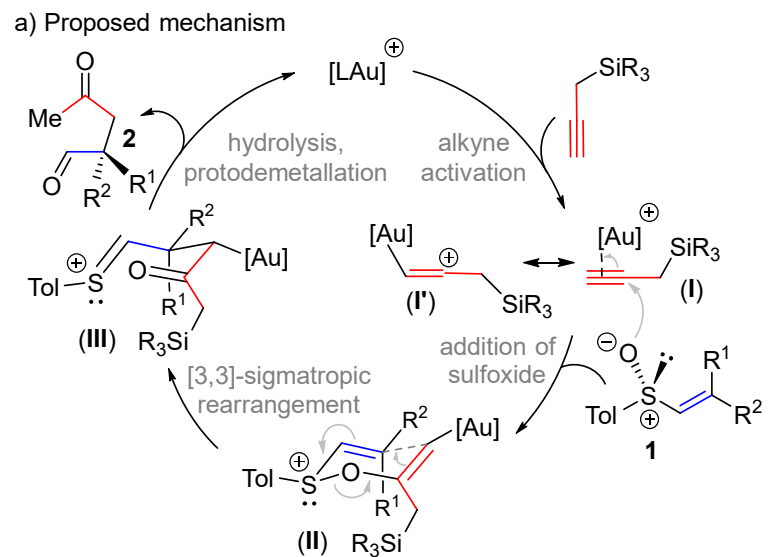

b) Stereospecific rearrangement

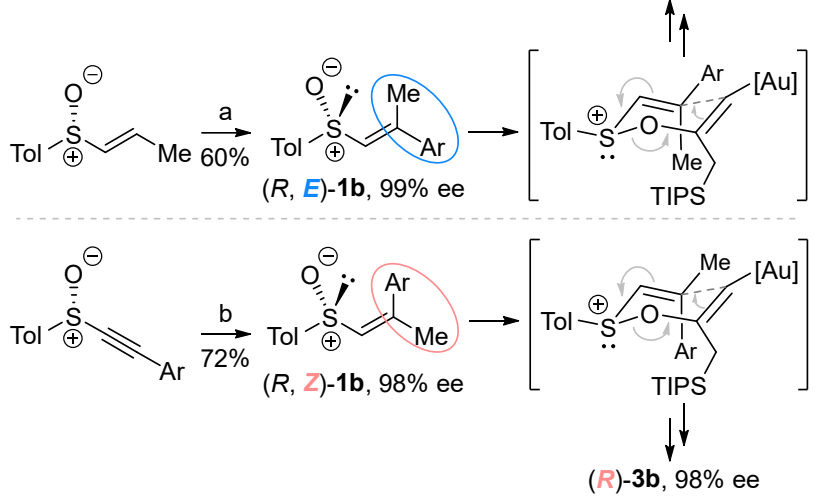

Reagents and conditions: (a) ArI, Pd(OAc) 2 (10 mol\%), dppp (10 mol\%), $\mathrm{Ag}_{2} \mathrm{CO}_{3}, \mathrm{DMF}, 100{ }^{\circ} \mathrm{C}, 36 \mathrm{~h}$; (b) $\mathrm{CuOTf}_{2}(2 \mathrm{~mol} \%$ ), $\mathrm{ZnMe}$, THF, - $78{ }^{\circ} \mathrm{C}$ to r.t., 12 h. dppp = 1,3-bis(diphenylphosphanyl)propane. $\mathrm{Ar}=p-\mathrm{Me}^{-} \mathrm{C}_{6} \mathrm{H}_{4}$.

This contrasts with the sole total synthesis, previously described in moderate overall yields $(<5 \%)$ and using a rather long synthetic pathway (16-17 steps). ${ }^{13 \mathrm{~b}}$

We then synthesized Enokipodin A and B (Scheme 5a, right), isolated from a culture broth of a mushroom "enokidake" (Flammulina velutipes) and possessing antimicrobial activities. ${ }^{14 a-b}$ Since both enantiomers of compound $\mathbf{3}$ could be isolated starting from either pure $E$ - or $Z$-isomers of vinyl sulfoxide 1, we investigated the isomerization of substrate $E$-1e to $Z$-1e, to have a straightforward access of both enantiomers of $\mathbf{3 e}$ from the same olefin. This was realized under UV lamp irradiation ( $365 \mathrm{~nm}$ ), over $15 \mathrm{~min}$ in acetonitrile (10/90: $E / Z$ ratio, $60 \%$ yield of enantiopure compound $Z$ $\mathbf{1 e}^{15}$ after recrystallization, see SI for the optimization table). After formation of $(R)-3 \mathbf{e}$, subsequent dimethylation and palladium-catalyzed hydrogenation of the double bond delivered 5 in 71\% yield. Then, boron tribromide deprotection or CAN oxidation steps furnished Enokipodin A and Enokipodin B in $24 \%$ and $32 \%$ overall yield respectively, over 6 steps. The asymmetric syntheses of these natural products are the shortest in terms of number of steps, with the highest overall yields described so far. ${ }^{14 c-f}$ Total syntheses shown below emphasize the importance of easy access to both enantiomers of $\mathbf{3}$ and the versatile functionalization of this small molecular "Swiss army knife". 
a) Synthesis of lagopodin A, hitoyopodin A, enokipodin A and B

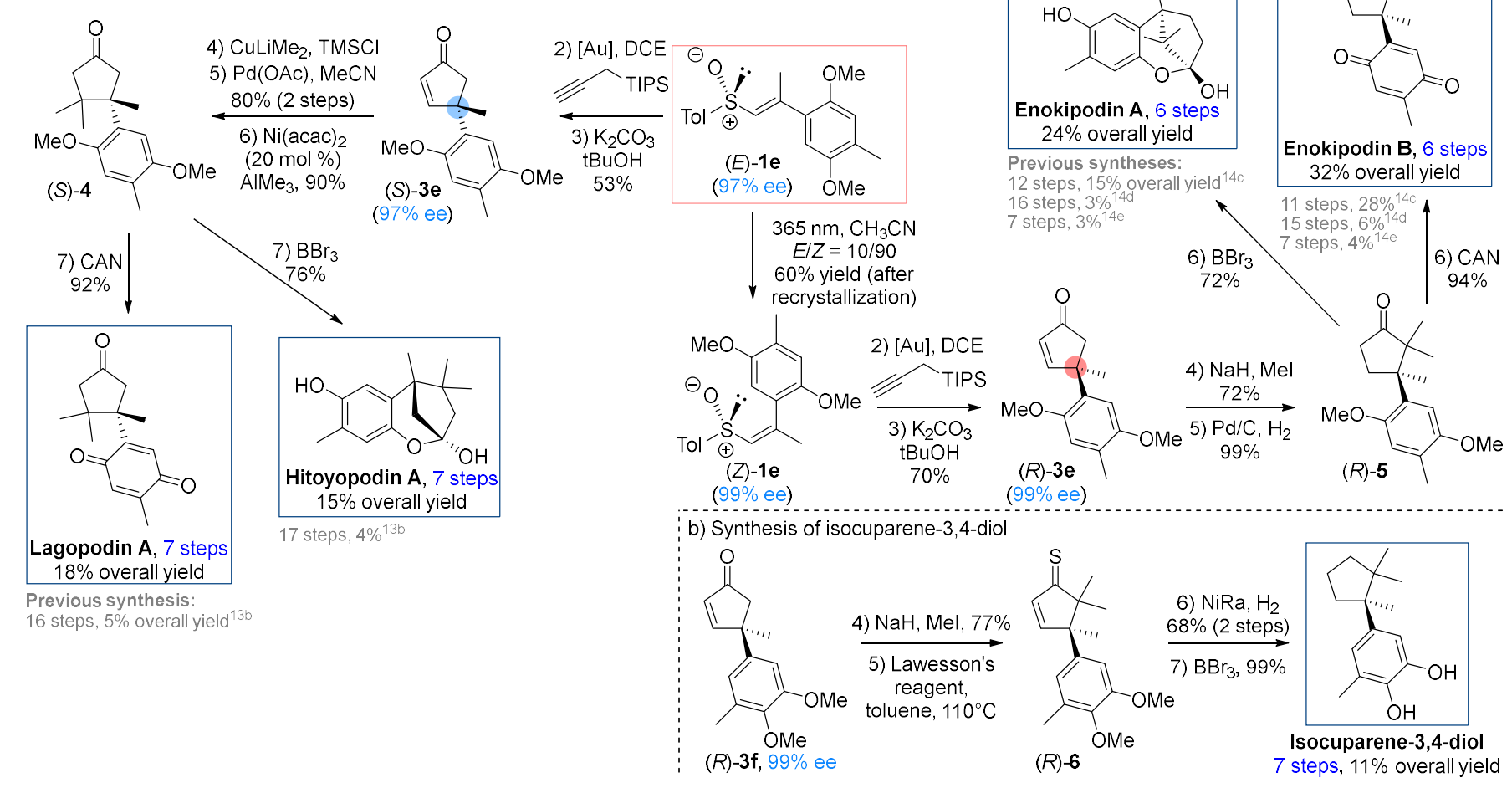

Finally, the sterically congested 1-aryl-1,2,2-trimethylcyclopentane natural product called isocuparene-3,4-diol ${ }^{16}$ was synthesized for the first time (Scheme $5 b$ ). With compound $(R)$-3f in hand, dimethylation, sulfuration, hydrogenation steps and then deprotection of the phenols delivered the desired compound in $11 \%$ overall yield over 7 steps. The ${ }^{1} \mathrm{H}$ and ${ }^{13} \mathrm{C}$ NMR spectra and $[\alpha]_{\mathrm{D}}{ }^{20}$ were in accordance with those of natural product $\left\{[\alpha]_{\mathrm{D}}^{20}-73.4(c 0.25\right.$, $\left.\mathrm{CHCl}_{3}\right)$; lit. $\left.{ }^{16}:[\alpha]_{\mathrm{D}^{20}}-73.6\left(c 0.35, \mathrm{CHCl}_{3}\right)\right\}$.

To examine the practicability of this newly developed gold-catalyzed methodology, we performed further investigations. Indeed, some divergent transformations on 2a provided in one step three different chiral structures of interest (Scheme 6). Aldolisation performed under mild conditions, at $40{ }^{\circ} \mathrm{C}$, formed alcohol 7 in $75 \%$ yield without further elimination reaction. Cyclobutane $\mathbf{8}$, possessing three contiguous stereogenic centers, was isolated via McMurry coupling ${ }^{17}$ (74\% yield, 3:1 dr). Finally, chiral 1,4-dihydropyridazine ${ }^{18} 9$ was isolated in $88 \%$ yield, by reaction of $\mathbf{2 a}$ with hydrazine.

\section{Scheme 6. Follow-up Transformations of $2 a$}

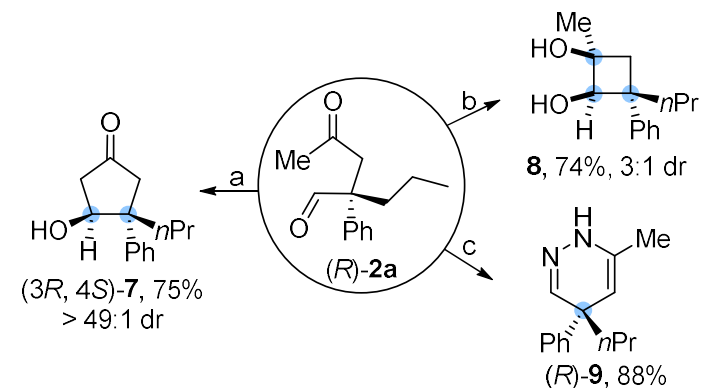

(a) $\mathrm{K}_{2} \mathrm{CO}_{3}$ (2.0 equiv), $t$ - $\mathrm{BuOH}, 40{ }^{\circ} \mathrm{C}, 96 \mathrm{~h}$; (b) $\mathrm{TiCl}_{4} /$ zinc dust: $1 / 1$, dry THF, $0{ }^{\circ} \mathrm{C}, 15 \mathrm{~min}$ and then reflux, $2.5 \mathrm{~h}$; (c) $\mathrm{NH}_{2} \mathrm{NH}_{2}, \mathrm{MeOH}$, reflux, $2 \mathrm{~h}$.

In conclusion, we have developed a new stereospecific transformation for the straightforward synthesis of cyclopentenones with C4-quaternary stereogenic centers. Enantioenriched products were easily obtained in two steps from cheap reagents and possess all the required functionalities for applications to short and efficient total syntheses of natural products, as illustrated by the total synthesis of five natural products. In the future, we plan to use this reaction as key step in the synthesis of more complex molecular targets. 


\section{AUTHOR INFORMATION}

\section{Corresponding Author}

Arnaud.voituriez@cnrs.fr

\section{Author Contributions}

All authors have given approval to the final version of the manuscript.

\section{ACKNOWLEDGMENT}

We thank the China Scholarship Council for a Ph.D. grant to W. Z. and the CNRS for financial support.

\section{REFERENCES}

(1) (a) Hawner, C.; Alexakis, A. Metal-catalyzed asymmetric conjugate addition reaction: formation of quaternary stereocenters. Chem. Commun. 2010, 46, 7295. (b) Feng, J.; Holmes, M.; Krische, M. J. Acyclic Quaternary Carbon Stereocenters via Enantioselective Transition Metal Catalysis. Chem. Rev. 2017, 117, 12564. (c) Bartáček, J.; Svoboda, J.; Kocúrik, M.; Pochobradský, J.; Čegan, A.; Sedlák, M.; Váňa, J. Recent advances in palladium-catalysed asymmetric 1,4-additions of arylboronic acids to conjugated enones and chromones. Beilstein J. Org. Chem. 2021, 17, 1048.

(2) (a) Ling, T.; Rivas, F. All-carbon quaternary centers in natural products and medicinal chemistry: recent advances. Tetrahedron 2016, 72, 6729. (b) Wang, Z. Construction of all-carbon quaternary stereocenters by catalytic asymmetric conjugate addition to cyclic enones in natural product synthesis. Org. Chem. Front. 2020, 7, 3815. Representative syntheses : (c) Hu, P.; Chi, H. M.; DeBacker, K. C.; Gong, X.; Keim, J. H.; Hsu, I. T.; Snyder, S. A. Quaternary-centreguided synthesis of complex polycyclic terpenes. Nature 2019, 569, 703. (d) Peng, C.; Arya, P.; Zhou, Z.; Snyder, S. A. A Concise Total Synthesis of (+)-Waihoensene Guided by Quaternary Center Analysis. Angew. Chem. Int. Ed. 2020, 59, 13521. (e) Brown, M. K.; Hoveyda, A. H. Enantioselective Total Synthesis of Clavirolide C. Applications of $\mathrm{Cu}$-Catalyzed Asymmetric Conjugate Additions and Ru-Catalyzed Ring-Closing Metathesis. J. Am. Chem. Soc. 2008, 130, 12904.

(3) Simeonov, S. P.; Nunes, J. P. M.; Guerra, K.; Kurteva, V. B.; Afonso, C. A. M. Synthesis of Chiral Cyclopentenones. Chem. Rev. 2016, 116, 5744

(4) (a) Brown, M. K.; May, T. L.; Baxter, C. A.; Hoveyda, A. H. AllCarbon Quaternary Stereogenic Centers by Enantioselective CuCatalyzed Conjugate Additions Promoted by a Chiral $N$-Heterocyclic Carbene. Angew. Chem. Int. Ed. 2007, 46, 1097. (b) Vuagnouxd'Augustin, M.; Kehrli, S.; Alexakis, A. Enantioselective Copper-Catalyzed Conjugate Addition to 2- or 3-Substituted Cyclopent-2-en1-ones: Construction of Stereogenic Quaternary Carbon Centers. Synlett 2007, 2057. (c) May, T. L.; Brown, M. K.; Hoveyda, A. H. Enantioselective Synthesis of All-Carbon Quaternary Stereogenic Centers by Catalytic Asymmetric Conjugate Additions of Alkyl and Aryl Aluminum Reagents to Five-, Six-, and Seven-Membered-Ring $\beta$-Substituted Cyclic Enones. Angew. Chem. Int. Ed. 2008, 47, 7358. (d) Ardkhean, R.; Mortimore, M.; Paton, R. S.; Fletcher, S. P. Formation of quaternary centres by copper catalysed asymmetric conjugate addition to $\beta$-substituted cyclopentenones with the aid of a quantitative structure-selectivity relationship. Chem. Sci. 2018, 9, 2628. (e) Kikushima, K.; Holder, J. C.; Gatti, M.; Stoltz, B. M. Palladium-Catalyzed Asymmetric Conjugate Addition of Arylboronic Acids to Five-, Six-, and Seven-Membered $\beta$-Substituted Cyclic Enones: Enantioselective Construction of All-Carbon Quaternary Stereocenters. J. Am. Chem. Soc. 2011, 133, 6902. (f) Gottumukkala, A. L.; Matcha, K.; Lutz, M.; de Vries , J. G.; Minnaard, A. J. PalladiumCatalyzed Asymmetric Quaternary Stereocenter Formation. Chem. Eur. J. 2012, 18, 6907.

(5) (a) Ito, Y.; Hirao, T.; Saegusa, T., Synthesis of $\alpha, \beta$-unsaturated carbonyl compounds by palladium(II)-catalyzed dehydrosilylation of silyl enol ethers. J. Org. Chem. 1978, 43, 1011. (b) Iosub, A. V.;
Stahl, S. S., Palladium-Catalyzed Aerobic Dehydrogenation of Cyclic Hydrocarbons for the Synthesis of Substituted Aromatics and Other Unsaturated Products. ACS Catalysis 2016, 6, 8201.

(6) (a) Vinogradov, M. G.; Turova, O. V.; Zlotin, S. G., Nazarov reaction: current trends and recent advances in the synthesis of natural compounds and their analogs. Org. Biomol. Chem. 2017, 15, 8245. (b) Lebœuf, D.; Wright, C. M.; Frontier, A. J. Reagent Control of $[1,2]$-Wagner-Meerwein Shift Chemoselectivity Following the Nazarov Cyclization: Application to the Total Synthesis of Enokipodin B. Chem. Eur. J. 2013, 19, 4835. (c) Chen, S.; Jiang, C.; Zheng, N.; Yang, Z.; Shi, L., Evolution of Pauson-Khand Reaction: Strategic Applications in Total Syntheses of Architecturally Complex Natural Products (2016-2020). Catalysts 2020, 10, 1199. (d) Yang, Z., Navigating the Pauson-Khand Reaction in Total Syntheses of Complex Natural Products. Acc. Chem. Res. 2021, 54, 556.

(7) (a) Enders, D.; Knopp, M.; Schiffers, R., Asymmetric [3.3]-sigmatropic rearrangements in organic synthesis. Tetrahedron-Asymmetry 1996, 7, 1847. (b) Jones, A. C.; May, J. A.; Sarpong, R.; Stoltz, B. M., Toward a Symphony of Reactivity: Cascades Involving Catalysis and Sigmatropic Rearrangements. Angew. Chem. Int. Ed. 2014, 53, 2556. Representative examples: (c) Calad, S. A.; Woerpel, K. A., Formation of Chiral Quaternary Carbon Stereocenters Using Silylene Transfer Reactions: Enantioselective Synthesis of (+)-5-epiAcetomycin. Org. Lett. 2007, 9, 1037. (d) Wang, K.; Bungard, C. J.; Nelson, S. G., Stereoselective Olefin Isomerization Leading to Asymmetric Quaternary Carbon Construction. Org. Lett. 2007, 9, 2325. (e) Uyeda, C.; Jacobsen, E. N., Enantioselective Claisen Rearrangements with a Hydrogen-Bond Donor Catalyst. J. Am. Chem. Soc. 2008, 130, 9228. (f) Linton, E. C.; Kozlowski, M. C., Catalytic Enantioselective Meerwein-Eschenmoser Claisen Rearrangement: Asymmetric Synthesis of Allyl Oxindoles. J. Am. Chem. Soc. 2008, 130, 16162. (g) Brown, C. J.; Bergman, R. G.; Raymond, K. N., Enantioselective Catalysis of the Aza-Cope Rearrangement by a Chiral Supramolecular Assembly. J. Am. Chem. Soc. 2009, 131, 17530. (h) Cao, T.; Deitch, J.; Linton, E. C.; Kozlowski, M. C., Asymmetric Synthesis of Allenyl Oxindoles and Spirooxindoles by a Catalytic Enantioselective Saucy-Marbet Claisen Rearrangement. Angew. Chem. Int. Ed. 2012, 51, 2448. (i) Tan, J.; Cheon, C.-H.; Yamamoto, H., Catalytic Asymmetric Claisen Rearrangement of Enolphosphonates: Construction of Vicinal Tertiary and All-Carbon Quaternary Centers. Angew. Chem. Int. Ed. 2012, 51, 8264. (j) Liu, Y.; Hu, H.; Lin, L.; Hao, X.; Liu, X.; Feng, X., Enantioselective construction of branched 1,3-dienyl substituted quaternary carbon stereocenters by asymmetric allenyl Claisen rearrangement. Chem. Commun. 2016, 52, 11963.

(8) Reviews : (a) Smith, L. H. S.; Coote, S. C.; Sneddon, H. F.; Procter, D. J. Beyond the Pummerer Reaction: Recent Developments in Thionium Ion Chemistry. Angew. Chem. Int. Ed. 2010, 49, 5832. (b) Huang, X.; Klimczyk, S.; Maulide, N. Charge-Accelerated Sulfonium [3,3]-Sigmatropic Rearrangements. Synthesis 2012, 44, 175. (c) Pulis, A. P.; Procter, D. J. C-H Coupling Reactions Directed by Sulfoxides: Teaching an Old Functional Group New Tricks. Angew. Chem. Int. Ed. 2016, 55, 9842. (d) Yorimitsu, H. Cascades of Interrupted Pummerer Reaction-Sigmatropic Rearrangement. Chem. Rec. 2017, 17, 1156. (e) Yanagi, T.; Nogi, K.; Yorimitsu, H. Recent development of ortho-C-H functionalization of aryl sulfoxides through [3,3] sigmatropic rearrangement. Tetrahedron Lett. 2018, 59, 2951. (f) Kaiser, D.; Klose, I.; Oost, R.; Neuhaus, J.; Maulide, N. Bond-Forming and -Breaking Reactions at Sulfur(IV): Sulfoxides, Sulfonium Salts, Sulfur Ylides, and Sulfinate Salts. Chem. Rev. 2019, $119,8701$.

(9) Gold-catalyzed processes : (a) Shapiro, N. D.; Toste, F. D. Rearrangement of Alkynyl Sulfoxides Catalyzed by Gold(I) Complexes. J. Am. Chem. Soc. 2007, 129, 4160. (b) Li, G.; Zhang, L. GoldCatalyzed Intramolecular Redox Reaction of Sulfinyl Alkynes: Efficient Generation of $\alpha$-Oxo Gold Carbenoids and Application in Insertion into R-CO Bonds. Angew. Chem. Int. Ed. 2007, 46, 5156. (c) Cuenca, A. B.; Montserrat, S.; Hossain, K. M.; Mancha, G.; Lledós, 
A.; Medio-Simón, M.; Ujaque, G.; Asensio, G. Gold(I)-Catalyzed Intermolecular Oxyarylation of Alkynes: Unexpected Regiochemistry in the Alkylation of Arenes. Org. Lett. 2009, 11, 4906. (d) Lu, B.; Li, Y.; Wang, Y.; Aue, D. H.; Luo, Y.; Zhang, L. [3,3]-Sigmatropic Rearrangement versus Carbene Formation in Gold-Catalyzed Transformations of Alkynyl Aryl Sulfoxides: Mechanistic Studies and Expanded Reaction Scope. J. Am. Chem. Soc. 2013, 135, 8512. (e) Zhou, W.; Voituriez, A., Gold(I)-Catalyzed Synthesis of Highly Substituted 1,4-Dicarbonyl Derivatives via Sulfonium [3,3]-Sigmatropic Rearrangement. Org. Lett. 2021, 23, 247. Key representative examples : (f) Yoshida, S.; Yorimitsu, H.; Oshima, K. 2-(2,2,2-Trifluoroethylidene)-1,3-dithiane Monoxide as a Trifluoromethylketene Equivalent. Org. Lett. 2009, 11 2185. (g) Kobatake, T.; Yoshida, S.; Yorimitsu, H.; Oshima, K. Reaction of 2-(2,2,2-Trifluoroethylidene)-1,3dithiane 1-Oxide with Ketones under Pummerer Conditions and Its Application to the Synthesis of 3-Trifluoromethyl-Substituted FiveMembered Heteroarenes. Angew. Chem. Int. Ed. 2010, 49, 2340. (h) Huang, X.; Maulide, N. Sulfoxide-Mediated $\alpha$-Arylation of Carbonyl Compounds. J. Am. Chem. Soc. 2011, 133, 8510. (i) Eberhart, A. J.; Imbriglio, J. E.; Procter, D. J., Nucleophilic Ortho Allylation of Aryl and Heteroaryl Sulfoxides. Org. Lett. 2011, 13, 5882. (j) Peng, B.; Huang, X.; Xie, L.-G.; Maulide, N. A Brønsted Acid Catalyzed Redox Arylation. Angew. Chem. Int. Ed. 2014, 53, 8718. (k) Yanagi, T.; Otsuka, S.; Kasuga, Y.; Fujimoto, K.; Murakami, K.; Nogi, K.; Yorimitsu, H.; Osuka, A. Metal-Free Approach to Biaryls from Phenols and Aryl Sulfoxides by Temporarily Sulfur-Tethered Regioselective C-H/C-H Coupling. J. Am. Chem. Soc. 2016, 138, 14582. (l) Fernández-Salas, J. A.; Eberhart, A. J.; Procter, D. J. Metal-Free CH-CH-Type Cross-Coupling of Arenes and Alkynes Directed by a Multifunctional Sulfoxide Group. J. Am. Chem. Soc. 2016, 138, 790. (m) Kaiser, D.; Veiros, L. F.; Maulide, N. Redox-Neutral Arylations of Vinyl Cation Intermediates. Adv. Synth. Catal. 2017, 359, 64. (n) Kaldre, D.; Maryasin, B.; Kaiser, D.; Gajsek, O.; González, L.; Maulide, N. An Asymmetric Redox Arylation: Chirality Transfer from Sulfur to Carbon through a Sulfonium [3,3]-Sigmatropic Rearrangement. Angew. Chem. Int. Ed. 2017, 56, 2212. (o) Shrives, H. J.; FernándezSalas, J. A.; Hedtke, C.; Pulis, A. P.; Procter, D. J. Regioselective synthesis of C3 alkylated and arylated benzothiophenes. Nat. Commun. 2017, 8, 14801. (p) Kaldre, D.; Klose, I.; Maulide, N. Stereodivergent synthesis of 1,4-dicarbonyls by traceless charge-accelerated sulfonium rearrangement. Science 2018, 361, 664.

(10) For the synthesis of vinyl sulfoxides 1a-s, three methodologies were used: 1) An olefination between (( $p$-tolylsulfinyl)methyl)phosphonate and different ketones: (a) Mikolajczyk, M.; Midura, W.; Grzejszczak, S.; Zatorski, A.; Chefczynska, A., J. Org. Chem. 1978, 43, 473. 2) Heck reaction: (b) Bachmann, D. G.; Wittwer, C. C.; Gillingham, D. G., Adv. Synth. Catal. 2013, 355, 3703. (c) Alonso, I.; Carretero, J. C., J. Org. Chem. 2001, 66, 4453. 3) Cu-catalyzed addition of organozinc reagents to alkynylsulfoxides: (d) Maezaki, N.; Sawamoto, H.; Suzuki, T.; Yoshigami, R.; Tanaka, T., J. Org. Chem. 2004, 69, 8387. General review: (e) Satoh, T. Development of new synthetic methods with aryl 1-chlorovinyl sulfoxides. Chem. Rec. 2004, 3, 329.

(11) (a) Lambert, J. B.; Wang, G. T.; Finzel, R. B.; Teramura, D. H., Stabilization of positive charge by $\beta$-silicon. J. Am. Chem. Soc. 1987, 109, 7838. (b) Lambert, J. B., The interaction of silicon with positively charged carbon. Tetrahedron 1990, 46, 2677. (c) Lambert, J. B.; Zhao, Y.; Emblidge, R. W.; Salvador, L. A.; Liu, X.; So, J.-H.; Chelius, E. C. The $\beta$ Effect of Silicon and Related Manifestations of $\sigma$ Conjugation. Acc. Chem.Res. 1999, 32, 183. (d) Eberhart, A. J.; Procter, D. J., Nucleophilic ortho-Propargylation of Aryl Sulfoxides: An Interrupted Pummerer/Allenyl Thio-Claisen Rearrangement Sequence. Angew. Chem. Int. Ed. 2013, 52, 4008. (e) Eberhart, A. J.; Shrives, H.
J.; Álvarez, E.; Carrër, A.; Zhang, Y.; Procter, D. J., Sulfoxide-Directed Metal-Free ortho-Propargylation of Aromatics and Heteroaromatics. Chem. Eur. J. 2015, 21, 7428. (f) Pons, A.; Michalland, J.; Zawodny, W.; Chen, Y.; Tona, V.; Maulide, N. Vinyl Cation Stabilization by Silicon Enables a Formal Metal-Free $\alpha$-Arylation of Alkyl Ketones. Angew. Chem. Int. Ed. 2019, 58, 17303. (g) Purinšs, M.; Mishnev, A.; Turks, M. r., Brønsted Acid Catalyzed 1,2-Silyl Shift in Propargyl Silanes: Synthesis of Silyl Dienes and Silyl Indenes. J. Org. Chem. 2019, 84, 3595.

(12) For representative example of syntheses of sesquiterpenes using chiral auxiliaries, see : (a) Meyers, A. I.; Lefker, B. A. Chiral bicyclic lactams for asymmetric synthesis of quaternary carbons. The total synthesis of (-)- $\alpha$-cuparenone. J. Org. Chem. 1986, 51, 1541. (b) Satoh, T.; Wakasugi, D. A novel synthesis of 2,4,4-trisubstituted 2-cyclopentenones by consecutive reaction of 1-chlorovinyl $p$-tolyl sulfoxides with acetonitrile and its homologues. Tetrahedron Lett. 2003, 44, 7517. (c) Spino, C.; Godbout, C.; Beaulieu, C.; Harter, M.; Mwene-Mbeja, T. M.; Boisvert, L. $p$-Menthane-3-carboxaldehyde: A Useful Chiral Auxiliary for the Synthesis of Chiral Quaternary Carbons of High Enantiomeric Purity. J. Am. Chem. Soc. 2004, 126, 13312 .

(13) (a) Bu'Lock, J. D.; Darbyshire, J. Lagopodin metabolites and artefacts in cultures of Coprinus. Phytochemistry 1976, 15, 2004. (b) Otaka, J.; Shimizu, T.; Futamura, Y.; Hashizume, D.; Osada, H. Structures and Synthesis of Hitoyopodins: Bioactive Aromatic Sesquiterpenoids Produced by the Mushroom Coprinopsis cinerea. Org. Lett. 2018, 20, 6294.

(14) (a) Ishikawa, N. K.; Yamaji, K.; Tahara, S.; Fukushi, Y.; Takahashi, K. Highly oxidized cuparene-type sesquiterpenes from a mycelial culture of Flammulina velutipes. Phytochemistry 2000, 54, 777. (b) Ishikawa, N. K.; Fukushi, Y.; Yamaji, K.; Tahara, S.; Takahashi, K. Antimicrobial Cuparene-Type Sesquiterpenes, Enokipodins $C$ and D, from a Mycelial Culture of Flammulina velutipes. J. Nat. Prod. 2001, 64, 932. (c) Kuwahara, S.; Saito, M. Enantioselective total synthesis of enokipodins A-D. Tetrahedron Lett. 2004, 45, 5047. (d) Yoshida, M.; Shoji, Y.; Shishido, K. Total Syntheses of Enokipodins A and B Utilizing Palladium-Catalyzed Addition of An Arylboronic Acid to An Allene. Org. Lett. 2009, 11, 1441. (e) Buter, J.; Moezelaar, R.; Minnaard, A. J. Enantioselective palladium catalyzed conjugate additions of ortho-substituted arylboronic acids to $\beta, \beta-$ disubstituted cyclic enones: total synthesis of herbertenediol, enokipodin A and enokipodin B. Org. Biomol. Chem. 2014, 12, 5883. (f) Note: another highly efficient total synthesis of enokipodin B was developed in 6 steps ( $34 \%$ overall yield, ref. 6 b), but with only $20 \%$ ee.

(15) Starting with 1-(2,5-dimethoxy-4-methylphenyl)ethan-1one and enantiopure sulfoxide(methyl)phosphonate, the HornerWadsworth-Emmons olefination afforded $(Z)-1 \mathrm{e}$ in $68 \%$ isolated yield (see Supporting Information for more details).

(16) Fukuyama, Y.; Asakawa, Y. Novel neurotrophic isocuparane-type sesquiterpene dimers, mastigophorenes A, B, C and D, isolated from the liverwort Mastigophora diclados. J. Chem. Soc., Perkin Trans. 1 1991, 11, 2737.

(17) Fürstner, A.; Bogdanović, B., New Developments in the Chemistry of Low-Valent Titanium. Angew. Chem. Int. Ed. Engl. 1996, 35, 2442.

(18) Combs, D. W.; Reese, K.; Cornelius, L. A. M.; Gunnet, J. W.; Cryan, E. V.; Granger, K. S.; Jordan, J. J.; Demarest, K. T., Nonsteroidal Progesterone Receptor Ligands. 2. High-Affinity Ligands with Selectivity for Bone Cell Progesterone Receptors. J. Med. Chem. 1995, 38,4880 . 